\title{
Jemaa el-Fnaa Public Square: A Cultural and Literary Source in Ben Jelloun's The Sand Child and The Sacred Night
}

\author{
Ruth Amar \\ University of Haifa, Haifa, Israel
}

\begin{abstract}
The purpose of this article is to analyze the significance of a special space, which has a particular meaning in Tahar Ben Jelloun's work: the public square of Jemaa el-Fnaa, Marrakesh's Medina Quarter. For Tahar Ben Jelloun, the well-known French Maghrebian writer, the process of writing begins with the emergence of creative evidence in speech. It is the matrix of his writing. Thus, an oral perspective is sketched out, a whole game of fleeting narratives told in the public square. This space is an ideal one that draws its elements from orality and contributes to the preservation of traditional knowledge and the implementation of common values participating in a collective memory. How does Ben Jelloun seize the voices that already exist in the real Public Square in order to engage them in his narrative? A closer examination of the text enables us to unpick the process of Ben Jelloun's narrative strategies. In the public square, the picture that emerges is that two essential elements reveal the organization of the narrative: the cultural source and the literary source.
\end{abstract}

Keywords: Jemaa el-Fnaa, process of writing, speech, storyteller

"Before writing a sentence, I say it loudly". 1

This event stimulates writing for Tahar Ben Jelloun. For this well-known French Maghrebian writer, the process of writing begins with the emergence of creative evidence in speech. This cultural experience is personal, sought after, proclaimed: it is the matrix of his writing. Thus, an oral perspective is sketched out, a whole game of fleeting narratives told in a place that has a particular meaning: the public square of Jemaa el-Fnaain Marrakesh's Medina Quarter (old city). The public square which Bsaithi considers as a shelter for oral tradition, is characterized as follows:

Sid Abdelouahab Square and other similar places in Morocco, the surviving example of which is Jemaa el-Fnaa in Marrakesh, were the center of an intense socio-cultural activity. This activity was popular and spontaneous. (Bsaithi, 2008, p. 107)

Recognized by UNESCO in the year 2001 as a "Masterpiece world heritage", for conveying urban legends and oral history, for the richness of the oral culture that it unfolds, Jemaa el-Fnaasquare, as a physical space, is a center for a rich oral tradition. The origin of its name is uncertain: Jemaa means "audience" in Arabic and "El Fna" means "a courtyard, in front of a building". Straight translation thus, would be "the

Ruth Amar, Lecturer, Department of Comparative Literature, University of Haifa.

1 T. Ben Jelloun, interview avec Stephan Bureau, Littérature: Contact, Radio Québec, 1993.

2 Djemaa El Fna, Top choice square in Djemaa El Fna \& Around, https://www.lonelyplanet.com/morocco/marrakesh/attractions/djemaa-el-fna/a/poi-sig/422043/1341479. 
audience area". The symbolic value of the physical public space is rooted in the collective socio-political consciousness as the basis for a general sense of civic action. The public square summons the high verb, the myth, the story, the anecdote, the event, oratory performance.

Being a territory of fragmented temporality, as well as a cultivated archaism of the myth, used by locals as a place of performance and spectacles, Jemaa el-Fnaa Square is the privileged space of Ben Jelloun's two most famous novels (forming together a diptych) The Sand Child and The Sacred Night. This space indeed, admits the differences of language, inciting the permissive act that plays with the coherence of the narrative, as well as that of the audience. The public square, is by definition fragile, evanescent, realized in the very prowess of the hlayqi'sact (the storyteller who generally activates the audience) and does not exist outside the circle of enunciation and reception. In effect, orality appeals on the daily exercise of an improvisation set on a rooted cultural basis whose motives it varies. Jemaa el-Fnaa brings together in a collective movement, fortuitous and individual intentions towards a "noble" goal: to transmit and perpetuate orally a heritage with a universal dimension. This space is an ideal one that draws its elements from orality and contributes to the preservation of traditional knowledge and the implementation of common values participating in a collective memory. Orality allows the author to express an origin, and communicate with societies with a written tradition. From then on, the spoken word turns to be inscribed in the texts to signify. Ait Mokhtar Hafida describes ben Jelloun's attitude towards the Magrebian culture in what follows:

In The Sacred Night, not only does Tahar Ben Jelloun borrow from his Maghrebian culture and heritage, but he also draws inspiration from the cultural text (The Thousand and One Nights) and from his mother tongue. Thus, the traces of orality in Ben Jelloun's text, as in other Maghrebian texts, explain that writing in the classical language always draws its source from the spoken word. ${ }^{3}$

The point is not that ben Jelloun takes a well-known genre formula to write his novels. The status of Ben Jelloun's writing appears to us in all its fruitful complexity: If the text is told vocally in which method is it written? The purpose of this article is to analyze Ben Jelloun's narrative strategies based on the public square as a metafictional element: How does Ben Jelloun seize the voices that already exist in the real Public Square of Jemaa el-Fnaa in order to engage them in his narrative? A closer examination of the text enables us to unpick the process of Ben Jelloun narrative strategies. In the public square, the picture that emerges is that two essential elements reveal the organization of the narrative: the cultural source and the literary source.

\section{The Cultural Source}

The Sand Child and The Sacred Night are impregnated with specific cultural characteristics as they appear in the public square, a territory created for public speech, a speech that evolves from circle to circle. It is undoubtedly a privileged place of transmission, conscious of an oral culture and it is not by pure chance that Ben Jelloun chooses this space to set out his stories. The two stories form a diptych composed of tales, customs, legends, rituals that play an essential role in the Maghreb community. The originality of Ben Jelloun lies in his art of seizing the aspects of the Maghreb tradition in a singular amalgam with the reality of the public square: the quest for a story as it usually occurs in Jemaa el-Fnaa square, different storytellers and the audience participation.

3 Ait Mokhtar Hafida, «Oralitéetécrituredans La Nuit sacrée de Tahar Ben Jelloun». http://www.univchlef.dz/uhbc/seminaires_2008/Communications_francais/Ait_Mokhtar_Ben_Jelloun.pdf. (This French text and all the following ones have been translated by myself). 


\section{The Quest for the Story}

The Sand Child and The Sacred Night reveal a continual search for the story: storytellers try to tell a story they do not understand. The public square then becomes the formal space where the narrative progresses, regresses, where it is modified or canceled not only by the storytellers who appear or disappear in turn, but also by the audience itself. It is in this privileged place that it is possible to memorize and it is there that orality engenders the story. Speech is reported and not simply said, because the tale is a quote from another tale, an inter-referential system ${ }^{4}$.

Ben Jelloun, in conveying the quest of the various storytellers in the public square, expresses at the same time his own compulsory search, nourished by a lack reflected in the Maghrebian postcolonial novel, a need to compensate for a past world, which is out of reach. Singularly, the narrative revealed, reflects the events and cultural elements of the Maghreb and at the same time, it discloses Ben Jelloun's own quest of the story: his novel is not the creation of a conventional story, but rather the process of creation itself, highlighted and becoming a narrative. The result is that it is not the story, but rather the manner it is conceived that is told.

Writing then covers all aspects of a literary discourse in formation. Ben Jelloun uses the deep gap that is created between content (Maghrebian legends, tales) and form (French language) between text and context. The text is then incomplete, fragmented, told and corrected in different ways by several narrators. The Sacred Night is a re-birth of the story that failed again and again in the mouth of many story tellers until the end in The Sand Child. The text of The Sacred Night is organized around a structure based on several competing storytellers-narrators who tell in turn, incomplete and fragmented stories in the halka (the circle around the storyteller). This narrative strategy is based on a speech that leads to another, chaos of the story as well as the hero, luring and blocking an impossible quest: "Friends, I owe you this story. I arrived at the moment when the storyteller responsible for saying it fell into one of those traps... ". The reader realizes immediately that he is a victim of the unaccountability of the story and that the plot is somewhat twisted: "Friends of good! What I am going to tell you is like the truth"6.

So we would be tempted to say that Ben Jelloun's work is more and more concerned with its internal process, and less and less about what it tells. Alain Robbe-Grillet commented on the fact that "the real writer has nothing to say. He only has his own way of telling it" (Barth, 1981, p. 400). Ben Jelloun's way would rather be to repeat the story by correcting it, each time, in a different manner. The result is a text, which stands with respect to its oral influence as well as its French writing, in a relationship that seems in some ways perplexing, yet which does not clearly situate itself outside or in opposition to these influence. It is a position much comparable to literary deconstruction. Through the narrative, the presentation of the writing process appears. The entire novel includes a meta-textual element, an inset thought that takes into account the typical cultural Maghrebian customs. The story and the production process related to culture make the work of the text become the narrative object itself. The restored word is a necessary work for the production of the Maghrebian narrative in a privileged cultural place: the public square.

\section{The Storytellers and Their Audience}

Ben Jelloun seizes voices already present in the public square, the most important of which is that of the oral storyteller. Oral storytellers exist in the Maghreb in large numbers: they have the talent to tell stories in a

\footnotetext{
${ }^{4}$ See Robert Elbaz's book, Le Discours maghrébin: dynamique textuelle chez Albert Memmi, Balzac Editions, 1988.

5 Tahar Ben Jelloun La Nuit sacrée, Seuil, 1988, p. 20.

${ }^{6}$ Ibidem, p. 6.
} 
society where one knows neither reading nor writing but where one is eager for oral tales. The entire Maghrebian atmosphere invites the audience to take part in the construction of the plot. The storyteller therefore, by speaking out, becomes a mediator between the audience and the story:

The skills of the hlayqi (the storyteller) are, in a way, in the experience of a social intelligence of an interactionist kind, that knows how to speak the languages of the Public Square, its codes, its mix and heterogeneity of norms, cultures, social situations... The hybrid, the differential, the conjunction, the disjunction, the Switch, the game of identity between oneself and the other, the mask and the truth of the suffering body, compose the grammatical routine of the hlayqi act. (Arrif, 2011).

Not only is the storyteller perceived as a showman whose goal is to entertain an audience, but he also serves to convey memories, ideals and to animate expectations. As Rahmouna Mehadji explains, the storyteller is considered "a wise man in the true sense of the term, a man whose faculty and will are to transmit didactic messages intended to perpetuate the ancestral values guarantors of the social order of the community" (Mehadji, 2005-2006, pp. 435-444). This remarkable practice is fundamental for the Maghreb community where speech has a role of transmitting a memory heritage. Rahmouna Mehadji adds that "each gathering gives the opportunity to tell a story: all meetings are a pretext to transmit knowledge through a word. Even today, in certain regions, there cannot be a meeting between people without a reason to tell stories" (Mehadji, 2005-2006, pp. 435-444).

An echo of this description is expressed by Nicole Belmont, writing about tales of the oral tradition, and the fact that the manner to tell is what is venerated: "when we advance [...] in knowledge and intimacy, we notice a strange phenomenon: the desire to tell the story calms down, or dies out since we understand that the storytelling says more and better" (Belmont, 1999, p. 237). This confirms the fact that the word itself has a particular strength. It is indeed around the storyteller, the central character of the public square that activates the orality, that the audience will gather and finally the story may be born. Then a frontal or solemn relationship is created between the storyteller and his audience. Mohammed Habib Samrakandi contends that this relationship "favors the power of the word on the public" and that "the storyteller [...] is involved in the community to perpetuate tradition" (Samrakandi, 2003, p. 8).

Ben Jelloun strongly covets the storyteller his active audience. He seems to be obsessed with the vital orality that he cannot afford to own completely since he is not an oral storyteller. His only possibility is to insert in his novel a storyteller to whom he tries to measure up. As a result, the text challenges the readers with their subconscious expectations and leads them to question the artful narrative pointers that have led them to such expectations. The readers may not have the pleasure of the usual canonic uncontested plot, but they are exposed to an eccentric discovery: a novel of orality created by dialogue with the voice of the storyteller who, most of the time, overlaps with that of the narrator to finally cover it completely as noted by Marc Gontard:

There is a pragmatic narrative whose protocol is a guarantee of social cohesion. In The Sand Child, the guaranteed narrator for the story order is the famous storyteller of Jemâa el FnaPublic Square in Marrakech, who draws his legitimacy from the halqa (the circle of listeners) and only his narrative performance in front of the public allows him to establish it (Gontard, 1994, p. 17)

The storyteller then becomes the "other" Ben Jelloun who is at the same time his assistant and his rival, often contradicted and sometimes illegitimate. In continuing to tell the story and at the same time questioning its being and its narrative construction, the narrator moves away from the traditional form of the French novel 
and distorts it by inserting his combative approach, oscillating between the French technical tools and the traditional oral storyteller and his audience. Orality and writing intertwine under one broad and this is one of the highlights of the text. This strategy is typical of the Maghrebian novel. Referring to the Albert Memmi's Desert, Robert Elbaz points out that:

Two voices interpenetrate each other; El-Mammi is the author of the novel, and at the same time the subject of narration and enunciation. His voice covers that of Memmi [...] Memmi speaks through El-Mammi and vice versa: in the body of the story the two voices meet [...] The preface and the postscript "contain" the narrative which, from the beginning till the end, consists of a quotation, in accordance with the expansive nature of the Maghrebian novel sign. (Elbaz, 1988, p. 142).

The expansion of the Maghrebiansign is also manifested in Ben Jelloun's Sand Child, but in a deeper manner, since there not one or two voices, but rather a plurality of overlapping voices, creating a shift in the relationship between the narrator and the storyteller. The confusion of the voices creates a disjunction, which contributes to the dismantling of the text.

Not only does Ben Jelloun use professional storytellers in his stories, but he also inserts amateur storytellers. A wide variety of these storytellers can be found in the Maghreb, who, even if they have talents more or less similar to those of professional storytellers, evolve in a different way. Unlike the first, who make their talent a job and are generally attached to a master when they are no longer themselves disciples, amateur storytellers, do not depend on anyone. They tell stories for their own pleasure in the sense that they do not consider this activity as a profession, and indeed, they do not expect any remuneration for their generally spontaneous performance. According to Rahmouna Mehadji, amateur storytellers:

occur more often in the evening, after a day's work, in private circles, intimate circles or in family circles where everyone can intervene, provided they respect the speech distribution protocol: begin first, those who have the perfect mastery of the text to be told, then come the women, and finally the youngest ones who try to learn the style of speech and the art of the composition of the tale. (Mehadji, 2005-2006, 435-444)

Therefore, amateur storytellers do not specialize in a particular register of oral tradition and do not seek to become specialists. They adopt several genres at once: tales or fables, epics or genealogies, proverbs or riddles.

These cultural characteristics, rooted in reality, are revealed in The Sand Child. The readers are immediately introduced in the context of the oral narrative in which the dialogical nature of the narrative is highlighted in a metafictional manner. The storyteller "sitting cross-leggedon a mat" in the square of Jamma Lafna, like a real professional, appears the day and disappears with the twilight, warning his audience: "This book, my friends, cannot circulate or be given ... It cannot be read by innocent spirits [...] You can access it without crossing my nights and my body" (Ben Jelloun, 1985, pp. 12-13). Insertions like "you know enough" create a theatrical suspense. The audience seated around the storyteller, takes part in the story by sudden interruptions, demonstrating the importance of orality and the theatrical atmosphere as it occurs in reality in Jemaa el Fnaa. Thus, as soon as the professional storyteller loses the power of credibility, he is interrupted by another who appears to be an amateur storyteller, who in turn presents himself as the true holder of knowledge and truth: "I, if I am allowed, will tell you the truth [...]. We will see if this story corresponds to the truth" (Ben Jelloun, 1985, p. 42-43). Then, a new amateur storyteller introduces himself as the brother of Fatima and undertakes the initiative of the story: "This man hides the truth from you. He is afraid to tell you everything" (Ben Jelloun, 1985, p. 67). He is also teased by the audience: "But you are not a storyteller ... You do not have 
the elegance of Si Abdel Malek, may God have his soul" (Ben Jelloun, 1985, p. 83-84). Then, another character of the halqa takes over: the story reminds him of another one, which is in fact, a miseen abyme of the main story, a microcosm that translates the macrocosm. This is the story of Antar: "a ruthless leader [...] an exemplary man [...] the day he died, it was revealed that this terror, this force lodged in a woman's body [...] today he is a saint; he is the marabout of wandering" (Ben Jelloun, 1985, p. 83-84).

Indeed, after the death of Si Abdelmalek, no less than five storytellers share the rest of the story: the three faithful listeners of the Halqa Salem, Amar and Fatouma ${ }^{7}$, the Blind Troubadour and the man with the blue turban, Bouchaïb, who reappears in The Sacred Night and finally disappears, devastated by the story. Such a technique thus not only does allow Ben Jelloun to use the traditional North African narrative mode, but also, as Marc Gontard emphasizes, on the literary level, it helps him "burst the monologue and integrate into his storyline a plural narrative that often contradicts itself with the mutation of the narrator / narratee hierarchy" (Gontard, 1993, p. 101). Overall, the skillful use of these strategies allows the reader to identify which narrative elements are emphasized by the author and what the structure and organization of the text are. In any case, Ben Jelloun enhances loose ends of the story to proliferate and then refuses to tie them together as a conclusion with a final version of events.

\section{The Literary Source: Legendary and Fairy Features}

The diptych of The Sand Child and The Sacred Night is established on the basis of Maghrebian tradition and culture as well as on its literary sources. Ben Jelloun's narrative strategies are established on a frothiness of stories before engaging in the main great narrative. For Robert Elbaz, these ambiguities and difficulties in grasping the plot imply a need of "pre-texts" long elaborated [...] which remain outside of the textual space, [for] the text itself is incapable of manifesting its own production process in the immediate future" (Elbaz, 1988, p. 35).

But these "pre-texts" accentuate the process of Maghrebian orality, expressed by other means, the most important of which are the legendary and fairy insertions in the text. The truth first proclaimed as a necessity in The Sand Child, becomes in The Sacred Night, more and more chaotic. Indeed, the linear facts are dotted with allusions and stories with marvelous characteristics.

For instance, on the day of his death, the father releases his son Ahmed, magically transformed into a daughter, Zahra: "The Night of Destiny calls you Zahra, flower of flowers ..." (Jelloun, 1988, p. 32). At this point, the rebirth process of the young woman begins. The journey to her new identity starts on the day of the father's burial which triggers a series of fairytales, more or less fantastic, qualified by Marc Gontard of "strange stories" (Gontard, 1993, p. 101).

In the same manner, in the cemetery, after the father's burial, exceptional characters appear such as the children playing on trees or the lovers hiding behind a tombstone to kiss. In the same way, the arrival of the bride on the white horse and the rider wearing a southern blue gandoura reinforces the fairy atmosphere. In a ceremonial manner of a magical fairy, the bride places on Zahra's shoulders a burnous embroidered with golden threads whispering in her ears that the rider "is waiting on a white mare spotted with gray" and the statement "the beautiful cavalier took me away" concludes the chapter entitled "A very beautiful day". The rider acts like a prince charming coming finally to release the princess after her transformation.

\footnotetext{
${ }^{7}$ In order to accentuate the orality and to highlight the fact that the storytellers are not professionals, Ben Jelloun does not hesitate to create a decadence of style: that of Salem, the black slave, is brutal, grotesque and vulgar; his story ends horribly. Amar's is already more poetic. But it is Fatouma, who is the most gifted of the three and who introduces herself as Ahmed-Zahra.
} 
Zahra has to undergo a whole series of ceremonial and symbolic acts, all of which come under fairy tales. Thus, in the following chapter entitled "The Perfumed Garden", she must be physically washed of all the anomalies that have concealed her body: the strips of fabric that tightened her breast are removed; she bathes in the springwater, symbol of maternity and origin of life. Her body is thus purified and she is reborn in a female body.

Moreover, after the physical assets, in order to transform her virgin body into that of a true woman, Zahra must undergo another act in the process of her rebirth: rape. In this case too, Ben Jelloun uses legendary effects. This time it is the tale of Little Red Riding Hood that he seems to be referring to. Just like the little girl is attacked by the wolf, Zahra is attacked but also unbound by her rapist, since without the initiation to the sexual act, she would not be a complete woman.

Other facts in The Sacred Night bear the characteristics of a fairytale, such as the monstrous figure of the Assise (the Khammam's keeper) which evokes that of the witches tales, or that of Zahra's uncle whose blood is "greenish yellow", and by killing him, Zahra does not commit a crime, but somehow gets rid of a dragon closely trailed behind by the witch. Zahra sometimes looks like Cinderella: she becomes a maid, she cleans the feet of the Consul, and when she is disliked by the Assise, she is sent back to the kitchen. As for the Consul, he has the role of Prince Charming who becomes "sacred" at the end of the story.

To summarize the elements of this study, we should remember that the public square plays a key role in Ben Jelloun's writing. He seizes the metafictional voices coming from the real Public Square of Jemaa el-Fnaa and inserts them in his diptych The Sacred Night and The Sand Child, in order to express the rites and the customs dear to his country, essential to him in order to write his story. In this space, two essential elements emerge to support the organization of the narrative: on the one hand, its cultural source which reveals elements such as the quest for a narrative, the storytellers and their active audience; on the other hand, its literary source which is articulated on the basis of legendary and fairy features.

\section{References}

Abdelmajid, A. (2011). La place Jamaâ Lafna, lieu patrimonial d'une oralité inventive (the Space Jamaâ Lafna, Patrimonial Place of Iventive Orality). intervention au colloque international La réinvention du «lien » en Méditerranée. Figures, formes, métamorphoses, ANR Imasud «Suds imaginaires, imaginaires desSuds: héritages, mémoires et patrimoine en Méditerranée», Marrakech, 1-3 mars.

Barth, J. (1981). La littérature du renouvellement: la fiction postmoderniste (The literature of renewal: The postmodern fiction). Poétique, 48, 395-405.

Belmont, N. (1999). Poétique du conte. Essai sur le conte de la tradition orale. Collection Le langage de contes, Editions Gallimard.

Ben Jelloun, T. (1985). L'Enfant de sable. Seuil.

Bsaithi, O. (2008). From Al Halka to Coca Cola posters: Aspects of change in public space in Oujda. In L. Touaf, \& S. Boutkhil (Eds.), The World as a Global Agora: Critical Perspectives on Public Space Social Science. Cambridge Scholar Publishing.

Elbaz, R. (1988). Le discours maghrébin: dynamique textuelle chez. Albert Memmi (The Magribean discourse: Textual dynamic in Albert Memmi's work). Préambule.

Gontard, M. (1993). Le récit méta-narratif chez Tahar Ben Jelloun in Tahar Ben Jelloun: stratégies d'écriture (The Méta-Narrative story in Tahar Ben Jelloun: stratégies d'écriture). Paris, L'Harmattan.

Mehadji, R. (2005-2006). Le conte populaire dans ses pratiques en Algérie (The pratics of popular story in Algeria). Retrieved from http://anneemaghreb.revues.org/151?lang=en\#tocto2n1

Samrakandi, M. H. (2003). Contes, conteurs et néo-conteurs, Les enjeux de l'oralité entre les deux rives de la méditerranée (Stories, story tellers and neo story tellers, the orality between two Mediterranean banks). Presses Universitaires du Mirail. 